\title{
Evaluation of amniotic fluid volume and its relation to perinatal outcome
}

\author{
Richa Dwivedi, Anju Depan, Kanti Yadav, Meenakshi Samariya*
}

Department of Obstetrics and Gynecology, JLN Medical College, Ajmer, Rajasthan, India

Received: 08 April 2019

Accepted: 08 May 2019

\section{*Correspondence:}

Dr. Meenakshi Samariya,

E-mail: anilsamariya14@gmail.com

Copyright: () the author(s), publisher and licensee Medip Academy. This is an open-access article distributed under the terms of the Creative Commons Attribution Non-Commercial License, which permits unrestricted non-commercial use, distribution, and reproduction in any medium, provided the original work is properly cited.

\begin{abstract}
Background: In pregnancy amniotic fluid surrounds the foetus and plays an important role in the development of fetus. From the very beginning of the formation of the extracoelomic cavity amniotic fluid can be detected. To evaluate the predictive value of amniotic fluid index (AFI) $(<5)$ for adverse perinatal outcome in terms of cesarean section for fetal distress, birth weight, meconium staining, Apgar scores, and NICU admission at birth.

Methods: This was a prospective study of 100 antenatal women visited RMC, Ajmer, Rajasthan, India during the year 2018 with gestational age >34 weeks. The women's history, clinical examination recorded, and AFI were measured and the perinatal outcome was compared between two groups, i.e., AFI $<5$ and $>5$.

Results: The cesarean section rate for fetal distress, low birth weight babies, $<2.5 \mathrm{~kg}$ and meconium staining was higher in patients with oligohydramnios $(\mathrm{p}=0.012,0.001,0.00015$ respectively). There was no significant difference in Apgar score at $5 \mathrm{~min}<7(\mathrm{p}=0.087)$ and NICU at birth between the two groups.

Conclusions: Oligohydramnios has a significant correlation with cesarean section for fetal distress, low birth weight babies and NICU admission.
\end{abstract}

Keywords: Apgar scores, Birth weight, Cesarean delivery, Meconium staining, Neonatal intensive care unit

\section{INTRODUCTION}

The modern obstetrics is concerned with the health and wellbeing of both the mother and the unborn child. Recognition of foetus at risk for death or damage in utero, quantifying the risk, balancing the fetal risk against the risk of neonatal complications from immaturity and determining the optimal time and mode of intervention are the cornerstones of modern perinatal medicine. ${ }^{1}$

Clinical estimation of amniotic fluid volume is an important part of fetal assessment as variation in its amount has been related to a variety of pregnancy complications. ${ }^{2}$ Quantification of amniotic fluid is an important component of the biophysical profile in ultrasound evaluation of the fetal wellbeing, especially in the third trimester. ${ }^{3}$

In pregnancy amniotic fluid surrounds the foetus and plays an important role in the development of fetus. From the very beginning of the formation of the extracoelomic cavity amniotic fluid can be detected. In early pregnancy, amniotic fluid is an ultrafiltrate of maternal plasma. By the beginning of second trimester it consists largely of extracellular fluid that diffuses through the fetal skin and thus reflect the composition of fetal plasma. After 20 weeks the cornification of fetal skin prevents this diffusion and it is composed largely of fetal urine. ${ }^{4}$ At first it is mainly water with electrolytes, but by about 12$14^{\text {th }}$ week the liquid also contain proteins, carbohydrates, 
lipids and phospholipid and urea, all of which aids in the growth of the fetus. ${ }^{5}$

The volume of amniotic fluid at each week is variable and is positively correlated with the growth of fetus. From the $10^{\text {th }}$ to $20^{\text {th }}$ week it increases from the $25 \mathrm{ml}$ to $400 \mathrm{ml}$ approximately. From the $8^{\text {th }}$ week when the fetal kidneys begin to function, fetal urine also contributes in the formation of the amniotic fluid. Approximately in the $10^{\text {th }}$ week the breathing and swallowing of the fetus slightly decrease the amount of amniotic fluid but neither urination nor swallowing contributes significantly to amniotic fluid quantity changes. Until the $25^{\text {th }}$ weeks when keratinization of skin is complete then the relationship between the amniotic fluid and the fetal growth stops. It reaches the plateau of $800 \mathrm{ml}$ at 40 weeks. The amount of fluid declines to roughly $250 \mathrm{ml}$ at 42 weeks. Assessment of amniotic fluid volume at term is often included in antepartum care as a method of evaluating fetal wellbeing. Alterations in AFI have classically been considered as an indicator of fetal compromise. ${ }^{6}$

So, the present study was conducted with the objective to study the association between amniotic fluid volume and perinatal outcome.

\section{METHODS}

Present cross-sectional comparative study was conducted among 100 antenatal women visited at OPD of Department of Obstetrics and Gynaecology at RMC, Ajmer, Rajasthan, India during January 2018 to December 2018 after ethical permission of institutional ethical committee. Inclusion criteria for participants were all low risk pregnant women with gestational age of 34 weeks or more with a singleton, non-anomalous fetus with intact membranes at the time of antepartum testing who were willing to participate in the study. Exclusion criteria were pregnant women with gestational age of less than 34 weeks, polyhydramnios, multiple pregnancy, placenta previa, fetal congenital anomalies, patients with rupture membranes, abnormal presentation and position, pregnancy with medical disorders. On admission a detailed history will be taken, and a clinical examination will be performed, and gestational age assessed. Amniotic fluid will be determined using the phelan's technique.

Study participants were divided into two groups based on their AFI.

- $\quad$ Group A : AFI $\leq 5 \mathrm{~cm}$

- Group B : AFI $>5 \mathrm{~cm}$

Amniotic fluid index has been measured by placing the pregnant women in supine position. The uterus has been divided into 4 quadrants using maternal sagittal midline vertically and an arbitrary transverse line approximately midway between the pubic symphysis and upper edge of the uterine fundus. Deepest, unobstructed, clear pocket of amniotic fluid has been visualized in each quadrant and all the 4 pockets of measurement has been summed together to determine the AFI with transducer held vertically.

At the time of delivery, the following variables has been collected nature of liquor were clear, thin or thick meconium, fetal heart rate monitoring by CTG (Cardio Tocography), mode of delivery. The end points used to judge perinatal outcome are fetal distress, non-stress test (NST), 1 minute and 5-minute APGAR score judged by independent observer-pediatrician. APGAR score less than 7 will be considered as abnormal, birth weight, frequency of admission to NICU, perinatal death-death of baby in the first 7 days, collected data will be analyzed with appropriate statistical test for final outcome. For continuous variables range, mean and standard deviation has been calculated and for categorical variables proportion and percentage has been obtained. To know the association between dependent and independent variables chi-square or z-test has been applied accordingly. $\mathrm{P}$ value less than 0.05 has been considered as statistically significant.

\section{RESULTS}

Table 1 shows that mean maternal age was $25 \pm 3.6$ in group A and $25 \pm 3.9$ in group B. Almost 28 (56\%) women were multiparous in group A and $30(60 \%)$ in group B. Gestational age was $>38-40$ weeks in $22(44 \%)$ in group A as compared to $24(48 \%)$ in group B. Around $30(60 \%)$ patients were induced in group A as compared to 18 $(36 \%)$ in group B. Group A 12 (24\%) were booked i.e. had at least 3 check up in hospital and at least one visiting third trimester of pregnancy and other 38 (76\%) were unbooked cases, in group B $21(42 \%)$ were booked cases while $29(58 \%)$ were un-booked cases.

\section{Table 1: Maternal demographic and obstetric characteristics.}

\begin{tabular}{|ll|l|}
\hline Variable & $\begin{array}{l}\text { Group A } \\
\text { AFI }<5 \\
(\mathbf{n}=50)\end{array}$ & $\begin{array}{l}\text { Group B } \\
\text { AFI }>5 \\
(\mathbf{n}=50)\end{array}$ \\
\hline Maternal age (mean) & $25 \pm 3.6$ & $25 \pm 3.9$ \\
\hline Maltiparous women & $28(56 \%)$ & $30(60 \%)$ \\
\hline $\begin{array}{l}\text { Gestational age }>38- \\
40 \text { weeks at delivery }\end{array}$ & $22(44 \%)$ & $24(48 \%)$ \\
\hline $\begin{array}{l}\text { Antenatal care } \\
\text { (Unbooked) }\end{array}$ & $38(76 \%)$ & $29(58 \%)$ \\
\hline Induction of labor & $30(60 \%)$ & $18(36 \%)$ \\
\hline
\end{tabular}

Table 2 shows that $12(24 \%)$ women in group A and 6 $(12 \%)$ women in group B had meconium-stained liquor. The difference was statistically significant $(\mathrm{p}=0.0005)$. Cesarean section was performed in $20(40 \%)$ women in group A as compared to $8(16 \%)$ in group B $(\mathrm{p}=0.012)$. Birth weight $<2.5 \mathrm{~kg}$ was found in $29(58 \%)$ patients in 
group A as compared to $13(26 \%)$ in group B. In group $\mathrm{A}$, the Apgar score at $1 \mathrm{~min}$ was $<7$ in eighteen women $(36 \%)$ as compared to $6(12 \%)$ in group $B(p=0.013)$. An Apgar score $<7$ at 5 min was noted in $16(32 \%)$ woman in group A and $4(8 \%)$ women in group $\mathrm{B}(\mathrm{p}=0.087)$. Nonreactive NST was present in a significant number of patients in group A $16(32 \%)$ as compared to group B 5 $(10 \%)(\mathrm{p}=0.00692)$. Most of the babies in group $\mathrm{A}$, that is $10(20 \%)$, were admitted to the neonatal intensive care unit (NICU). However, in group B, 6 (12\%) babies were admitted to the NICU ( $p<0.05)$.

Table 2: Obstetric and perinatal outcome.

\begin{tabular}{|llll|}
\hline Variable & $\begin{array}{l}\text { Group A } \\
\text { AfI }<5 \\
(n=50)\end{array}$ & $\begin{array}{l}\text { Group B } \\
\text { AFI }>5\end{array}$ & p value \\
$(n=50)$ & Meconium- \\
$\begin{array}{l}\text { Mtained liquor } \\
\text { sesarean for fetal }\end{array}$ & $12(24 \%)$ & $6(12 \%)$ & 0.00015 \\
\hline $\begin{array}{l}\text { Cestress } \\
\text { distre }\end{array}$ & $8(16 \%)$ & 0.012 \\
\hline $\begin{array}{l}\text { Birth weight } \\
<2.5 \text { kg }\end{array}$ & $29(58 \%)$ & $13(26 \%)$ & 0.001 \\
\hline APGAR score & $18(36 \%)$ & $6(12 \%)$ & 0.0138 \\
\hline 1 min $<7$ & $16(32 \%)$ & $4(8 \%)$ & 0.087 \\
\hline 5 min $<7$ & $16(32 \%)$ & $5(10 \%)$ & 0.00692 \\
\hline $\begin{array}{l}\text { Non-Reactive } \\
\text { NST }\end{array}$ & $10(20 \%)$ & $6(12 \%)$ & 0.001 \\
\hline $\begin{array}{l}\text { Admission to } \\
\text { NICU }\end{array}$ & & \\
\hline
\end{tabular}

\section{DISCUSSION}

This study was conducted on pregnant women of the gestational age of 34 weeks and beyond admitted to RMC, JLN Medical College, Ajmer, Rajasthan, India.

The mean age in present study was $25 \mathrm{yrs}$ in both the groups which is comparable to mean age 25.87 years in similar study conducted by Ghike $\mathrm{S}$ et al. ${ }^{7}$ The mean gravidity in present study is 2.22 in group A and 2.54 in group B which is comparable to mean gravidity of 2 in study conducted by Baron $\mathrm{C}$ et al. ${ }^{8}$ The mean gestational age in the present study is 37.92 weeks in group $\mathrm{A}$ and 38.02 weeks in group B which is comparable with mean gestational age of 37.5 weeks in the study conducted by Casey BM et al. ${ }^{9}$

Induction of labour was $60 \%$ in group A as compared to $36 \%$ in group $\mathrm{B}$ which is statistically significant $(\mathrm{p}=0.016)$ and this is consistent with the study done by Casey BM et al (42\%). ${ }^{9}$ The incidence of meconium stained amniotic fluid was higher in women with AFI <5 $\mathrm{cm}$. The thick meconium stained liquor was noted in $24 \%$ in the study group A (AFI $<5 \mathrm{~cm}$ ). In this study, which is not consistence with the study done by Rutherford SE et al, $(54.0 \%)$ and Sriya R et al, $(38.9 \%) .{ }^{10-11}$ Chauhan SP et al, in the meta-analysis found that intrapartum AFI $<5 \mathrm{~cm}$ was associated with increased incidence of cesarean section specially for fetal distress, which was similar to this study. ${ }^{12}$ Rutherford SE et al, found an inverse relationship between amniotic fluid index and cesarean section. $^{4}$

In the present study, authors found that non-reactive NST was present in significant number of patients in group A (32\%) as compared to group B $(10 \%)$. Results found are statistically significant. Bhagat $\mathrm{M}$ et al, found that Nonreactive NST was present in a significant number of patients in AFI <5 (32\%) as compared to AFI >5 (9.7\%) $(\mathrm{p}=0.002)$ and Rutherford SE et al, found an inverse relationship between the amniotic fluid index and nonreactive nonstress tests (NST). ${ }^{10,13}$ In the present study, the 1 minute Apgar score was $<7$ in $18 \%$ in group A, whereas only $6 \%$ babies in group 2 had a 1 minute Apgar score $<7 \quad(p=0.0138, S)$. The 5 minutes Apgar score was $<7$ in $16 \%$ in group A and $4 \%$ in group B and this difference was statistically significance $(p=0.087$, NS). A study by Grubb et al, found that the 1 minute Apgar score $<7$ in $84 \%$ patients with AFI $<5 \mathrm{~cm}$ as compared to $14 \%$ in the normal AFI group, which was highly significant $(\mathrm{p}=0.01) .{ }^{14}$ In the same study, the 5 minutes Apgar score $<7$ was seen in $13 \%$ patients with AFI $<5 \mathrm{~cm}$ vs $5 \%$ in the normal AFI group.

In the current study, birth weight $<2.5 \mathrm{~kg}$ was found in 29 $(58 \%)$ of the patients in group 1 versus $13(26 \%)$ in group 2 , and the difference was statistically significant $(\mathrm{p}=0.0013)$. Bhagat $\mathrm{M}$ et al, found that birth weight $<2.5$ $\mathrm{kg}$ was found in $14(56 \%)$ of the patients in AFI $<5$ versus $38(21.7 \%)$ in $\mathrm{AFI}>5$, and the difference was statistically significant $(p=0.001) .{ }^{13}$ The incidence of admission to NICU was $20 \%$ in group A as compared to $12 \%$ in group $\mathrm{B}$ and this is consistent with studies by Megann EF et al, (7\%) and Casey BM et al, (7.6\%) however the results is not consistent with studies by Sriya R et al $(88 \%){ }^{9,15}$

\section{CONCLUSION}

The above study concluded that amniotic fluid is a helpful tool in determining high risk patients during labour and AFI $\leq 5 \mathrm{~cm}$ is one of the indicators of comparatively poor perinatal outcome. The high statistical significance between low AFI and occurrence of non- reassuring FHR, LSCS for foetal distress and incidence of thick meconium stained liquor would help to identify patients who needs intensive monitoring during labour and may land up in emergency caesarean section.

So, AFI when used as an 'admission test' in intrapartum period can categorize the fetuses into 'high risk' and 'low risk' depending on their susceptibility to FD. In the presence of low AFI, the incidence of MSL, abnormal FHR, low APGAR score, rate of LSCS, low birth weight, non-reactive NST, NICU admissions. So, determination of AFI can be used as an adjunct to other fetal surveillance methods to identify fetuses at risk of poor perinatal outcome. 
Funding: No funding sources

Conflict of interest: None declared

Ethical approval: The study was approved by the Institutional Ethics Committee

\section{REFERENCES}

1. Manning FA. Antepartum fetal testing: a critical appraisal. Curr Opin Obstet Gynecol. 2009;21(4):348-52.

2. Ravi SA, Priya S, Priya P, Radhakrishnan S. Normal and abnormal liquor volume and its correlation with perinatal outcome. New Indian J OBGYN. 2019;5(2):113-9.

3. Kofinas A, Kofinas G. Differences in amniotic fluid patterns and fetal biometric parameters in third trimester pregnancies with and without diabetes. J Matern Fetal Neonatal Med. 2006;19(10):633-8.

4. Pawilowicz OM, Jawien E, Deja S, Hirnle L, Zabek A, Mlynarz P. Metabolomics of human amniotic fluid and maternal plasma during normal pregnancy. PLoS One. 2016;11(4):e0152740.

5. Truswell SA, Weininger J, Carpenter K, Douglas W. Jones DW. Human nutrition. Encyclopædia Britannica, Inc, 2018. Available at: https://www.britannica.com/science/human-nutrition. Accessed on 8 April 2019.

6. Tripathi U, Khatod N, Agrawal V. Evaluation of amniotic fluid volume and its relation to perinatal outcome. J Evol Med Dental Sci. 2015;4(37):6451-5.

7. Ghike S. Increasing severity of oligohydramnios: a risk factor for outcome. J SAFOG 2013;5:8-10.

8. Baron C, Morgan MA, Garite TJ. The impact of amniotic fluid volume assessed intrapartum on perinatal outcome. Am J Obstet Gynecol. 1995;173(1):167-74.

9. Casey BM, Intire DD, Donald D. Pregnancy outcome after diagnosis of oligohydramnios at or beyond 34 weeks of gestation. Am J Obstet Gynecol. 2000;182:902-12.

10. Rutherford SE, Jeffrey P, Phelan J, Smith CV, Jacobs N. The four-quadrant assessment of amniotic fluid volume: an adjunct to antepartum fetal heart rate testing. Obstet Gynecol. 1987;70:353.

11. Sriya R, Singhai S. Perinatal outcome in patients with amniotic fluid index $\leq 5 \mathrm{~cm}$. J Obstet Gynaecol India 2001;51(5):98-100.

12. Chauhan SP, Sanderson M. Perinatal outcome and amniotic fluid index in the antepartum and intrapartum period: a meta analysis. Am J Obstet Gynaecol. 1999;181:1473-8.

13. Bhagat M, Chawla I. Correlation of amniotic fluid index with perinatal outcome. J Obstet Gynaecol India. 2014;64(1):32-5.

14. Grubb DK, Paul RH. Amniotic fluid index and prolonged antepartum fetal heart rate decelerations. Obstet Gynecol. 1992;79:558-60.

15. Magann EF, Chouhan SP, Kinsella MJ. Antenatal testing among 1001 patients at high risk: the role of ultrasonographic estimate of amniotic fluid volume. Am J Obstet Gynecol. 1999;180:1330-6.

Cite this article as: Dwivedi R, Depan A, Yadav K, Samariya M. Evaluation of amniotic fluid volume and its relation to perinatal outcome. Int J Reprod Contracept Obstet Gynecol 2019;8:2449-52. 